\title{
Los iniciadores de la ortopedia en México
}

\author{
The initiators of orthopedics in Mexico
}

José Luis Gómez De Lara*

\footnotetext{
Palabras clave: Medicina, ortopedia, cirugía, cirujano, amputación.

Key words: Medicine, orthopedics, surgery, surgeon, amputation.
}

\section{RESUMEN}

El año de 1833 es significativo en la evolución de la medicina mexicana debido a la fundación del Establecimiento de Ciencias Médicas, que fusionó la medicina con la cirugía e inició una nueva época para la medicina en nuestro país, aunque por la inestabilidad política, el Establecimiento tuvo que peregrinar por diferentes sitios. En ese lugar y hospitales, médicos y cirujanos como Luis Muñoz, Pedro Escobedo y Rafael Lavista comenzaron a interesarse por la cirugía del sistema musculoesquelético, aportando con sus enseñanzas e investigaciones al surgimiento y desarrollo de la ortopedia nacional.

\section{ABSTRACT}

The year 1833 is significant in the evolution of medicine in Mexico due to the foundation of the Establecimiento de Ciencias Médicas, that fused medicine with surgery, starting a new era in medicine in our country, although due to the political unrest, the Establecimiento had to move several times. Doctors and surgeons such as Luis Munoz, Pedro Escobedo and Rafael Lavista became interested in surgery of the musculoskeletal system, contributing with their teachings and research to the emergence and development of national orthopedics.

\section{INTRODUCCIÓN}

A pesar de las guerras y conflictos internos por los que atravesó el país, la medicina del siglo XIX en México contó con figuras que incorporaron las técnicas europeas a nuestro medio científico y desarrollaron procedimientos innovadores como la cirugía de trauma y ortopedia, la anestesia por bloqueo y transrectal, manejo de los abscesos hepáticos, entre otros adelantos que constituyeron aportaciones a la ciencia médica universal.

La revolución médica que cobró auge en los países europeos se reflejó también en México gracias a los esfuerzos de Manuel Eulogio Carpio (1791-1855), que dio a conocer el estetoscopio de René Laënnec (1781-1826), y del médico poblano Miguel Francisco Jiménez (1813-1875), fundador de la clínica moderna mexicana. Ambos se encargaron de renovar su enseñanza, divulgar y practicar las nuevas técnicas y, sobre todo, de adaptarlas a las condiciones y enfermedades propias del país. ${ }^{1}$

En este contexto de cambios en la medicina, resulta de interés rescatar la figura de aquellos médicos y cirujanos que comenzaron a interesarse en las enfermedades del aparato locomotor. El primero de ellos fue José Miguel Muñoz González, cirujano militar de origen mexicano que desarrolló no sólo su capacidad clinicoquirúrgica, sino que también brindó elementos en el campo de la oftalmología, la ginecología y obstetricia, y principalmente, en el campo de la ortopedia; asimismo, creó reformas en los estudios médicos y fue encargado de conservar la vacuna contra la viruela. El segundo cirujano, autor de importantes técnicas quirúrgicas y profesor por oposición de clínica quirúrgica en la Escuela Nacional de Medicina, fue Francisco Montes de Oca, quien contribuyó al desarrollo de la ortopedia nacional. Conozcamos un poco más sobre su trabajo.

\section{Las contribuciones quirúrgicas de Francisco Montes de Oca}

Francisco Montes de Oca (1837-1885) fue un hábil cirujano de gran reconocimiento internacional, creador de dos magníficas técnicas quirúrgicas que surgieron del conocimiento
Recibido: 20/01/2016 Aceptado: 02/05/2016 
anatómico preciso y su buena aplicación. La primera de ellas fue la amputación de la pierna por debajo de la rodilla con la conservación de un colchón muscular de los gemelos para recubrir un muñón bien acolchonado. Ejecutó por primera vez esta amputación en un cadáver en el hospital militar a mediados de 1878, y después, en un paciente vivo en el Hospital de San Hipólito. ${ }^{2}$

Esta operación es un procedimiento de amputación por incisión en raqueta (Figura 1), la que se procura dejar en la parte anterior de la pierna y un poco afuera de la cresta de la tibia, con una ondulación en el corte posterior en forma de $S$ itálica, para que así resulte una cicatriz bilateral no mediana, desviada un poco hacia fuera. ${ }^{2}$ Se dice que con este procedimiento jamás se gangrena el muñón y queda artísticamente adaptable para el uso de una prótesis por su buena confección.

Las anteriores técnicas consistían en que el paciente era tratado con un solo corte y se aserraba el hueso en el mismo lugar donde se cortaban la piel y el músculo. La consecuencia era que lo que quedaba de la pierna era muy molesto para colocar una prótesis, por lo que algunos individuos preferían no usarla; asimismo, era muy doloroso tener el hueso casi expuesto, o se ulceraba y, finalmente, se infectaba el muñón.

No se sabe a ciencia cierta si Montes de Oca copió o modificó el modelo del antiguo

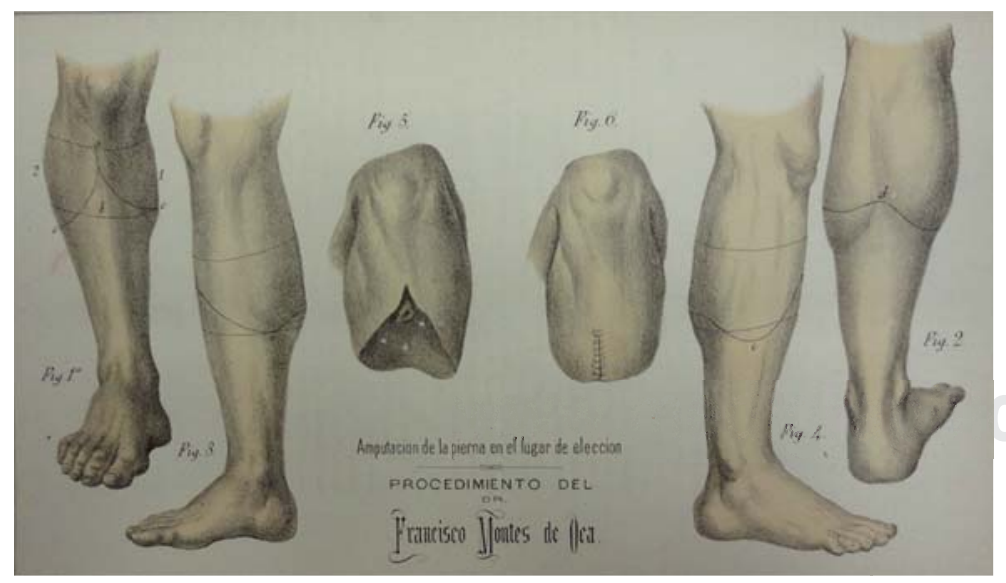

Figura 1. Amputación de la pierna. Incisión en raqueta.

Fuente: Escuela de Medicina. Periódico dedicado a las Ciencias Médicas. Tomo Quinto, 1883-1884. pp. 45. cirujano inglés Lowhan; lo cierto que este médico europeo había concebido un modelo parecido donde se dejaba cierta porción de piel y se cubría el hueso aserrado para impedir úlceras o dolores después de operado. Montes de Oca se permitió acomodar un colgajo de los músculos posteriores de la pierna a fin de lograr un "colchón", una prótesis que le permitió al muñón colocarse de manera más cómoda, sin dolor ni riesgo de hacer úlceras, con el objetivo de llevar una vida un poco más tolerable. Es interesante que Montes de Oca diseñara su técnica hacia 1875 y que en 1880 se diera una discusión entre el cirujano Le Fort y nuestro médico militar, arguyendo que la primacía era del francés. ${ }^{3}$

La segunda técnica de Montes de Oca fue la introducción de la desarticulación del hombro, que ensayó por primera vez durante el sitio en Puebla puesto por el ejército francés en 1863 y que sería publicada por él en 1874 al presentar su tesis para la oposición a la cátedra de Clínica Externa de la Escuela de Medicina. ${ }^{4}$ Más que una técnica propia, modificó el procedimiento de Dominique Jean Larrey (1766-1842) para la desarticulación del hombro, que explicó a detalle en el concurso a la plaza adjunta de Clínica Externa. Al mismo tiempo, hizo una comparación entre ambas técnicas y explicó las ventajas de su método sobre el de Larrey: "Creo, pues, que las modificaciones que propongo son tanto más de aceptarse cuanto que la práctica, aunque todavía en pequeña escala, las recomienda. De diez individuos que cuento operados por este método, no he tenido un solo mal resultado. Los tres primeros fueron operados en el Hospital de San Juan de Dios en Puebla en 1863, durante el sitio francés; tres operé durante el sitio de México en 1867, y se salvaron también. Uno de estos operados es un coronel, hoy retirado. Los cuatro últimos fueron operados el 2 de octubre de 1871 en el Hospital de San Lucas después del asalto de la Ciudadela". ${ }^{5}$

La técnica de Montes de Oca fue posteriormente superada por otra del doctor zacatecano Fernando López Sánchez y Román. Él fue discípulo predilecto del doctor Francisco Montes de Oca, profesor de Cirugía de Guerra en la Escuela Médico Militar en el año 1881, creador de la clínica de oftalmología en el 
Hospital Militar durante 1886 y fundador de la Cruz Roja en 1909. En el año 1901 aplicó la cocaína como anestésico ocular por primera vez en México. ${ }^{6}$ Uno de sus trabajos destacados en el campo de la "ortopedia" fue la invención de un nuevo procedimiento de desarticulación del hombro en 1893 que superaba la propuesta por Montes de Oca. En este procedimiento se conservaba en toda su integridad el deltoides, sin perturbar ni su inervación ni su irrigación; con una incisión en raqueta, piel y deltoides, se levantaba el colgajo y se abordaba la articulación sin perturbar la integridad del músculo. ${ }^{7}$ Montes de Oca, además de proponer una técnica para desarticular el hombro, describió en la misma tesis una desarticulación de los cuatro últimos metacarpianos, así como una operación para extirpar el testículo. Trataba las heridas utilizando el Licor de Labarreque. ${ }^{5}$

Admiró el trabajo del cirujano de los ejércitos napoleónicos, barón Dominique Jean Larrey, cirujano militar francés, innovador de conocimientos prácticos y de gran erudición. Fue creador de carros ambulantes (ambulancias) para trasladar rápidamente al médico al lugar donde eran necesarios sus servicios y para transportar igualmente a los heridos a los puestos de socorro, pero fue más conocido por su labor quirúrgica. ${ }^{8}$ Son memorables sus contribuciones sobre las indicaciones y las técnicas de amputaciones en extremidades, sobre todo inferiores, el manejo quirúrgico y el tratamiento de las heridas al realizar lo que ahora conocemos como liberación de compartimentos y fasciotomías. ${ }^{9}$ Se menciona que Dominique Jean Larrey ${ }^{9}$ amputó más extremidades que cualquier otro médico. En sus memorias señala que realizó unas 200 amputaciones supracondíleas en un solo día durante la batalla de Borodino. Amputaba las extremidades muy dañadas dentro de las primeras cuatro horas y no 10 o 20 días después, que era lo habitual. La amputación temprana resultaba más sencilla, menos dolorosa, se perdía menos sangre y se infectaba menos. Si se asume que trabajó las 24 horas, debió haber efectuado una amputación cada siete minutos.

Volviendo con nuestro personaje, alcanzó en el año de 1882 el grado de general brigadier en reconocimiento a la ayuda que prestó al ejército mexicano y fue inspector del Cuerpo
Médico Militar. Tiempo atrás, en 1868, ingresó a la Academia Nacional de Medicina. Fue fundador, en 1874, y primer presidente de la Asociación Médico-Quirúrgica Larrey, la cual editó la primera revista de trauma en Latinoamérica, conocida como Anales de la Sociedad Larrey, donde se publicaron, entre otros, trabajos dedicados a la ortopedia mexicana. En ese mismo año, ganó por oposición la plaza de adjunto a la cátedra de Clínica Externa en la Facultad de Medicina. Murió a la temprana edad de 48 años el 14 de marzo de 1885 en Apan, Estado de Hidalgo, a causa de una neumonía aguda.

\section{Luis Hidalgo y Carpio}

La cirugía tuvo, asimismo, brillantes médicos mexicanos que se beneficiaron con los adelantos científicos y destacaron en la lucha contra las enfermedades y lesiones que aquejaban al aparato locomotor. Así, por ejemplo, tenemos la imagen del médico poblano Luis Hidalgo y Carpio (1818-1879) (Figura 2), que durante sus 26 años de servicio en el Hospital de San Pablo (ahora Hospital Juárez) realizó 28 desarticulaciones escápulo-humerales, todas en adultos, excepto dos que fueron en niños de una edad aproximada de 12 años; de ellas, 25 se practicaron en hombres y tres en mujeres. ${ }^{10}$

Para entonces, antes de 1860, predominó la técnica del cirujano favorito de Napoleón, Larrey, para hacer el procedimiento de desarticulación de hombro. No se encuentran antecedentes de alguna desarticulación de hombro antes de 1800, por lo que Hidalgo y Carpio representa uno de los precursores de la ortopedia en nuestro país; quizá otros muchos cirujanos la hayan realizado antes de dicho año, pero, por desgracia, son muy escasos los trabajos que lo describen; mérito mayor para el doctor Hidalgo y Carpio, quien actuó no sólo como autor de artículos en la Gaceta Médica de México, sino también como editor e impulsor de ese conocimiento científico. ${ }^{11}$

Hidalgo y Carpio fue el segundo médico en realizar con éxito en América Latina la desarticulación coxo-femoral (separación de la cabeza del fémur de la fosa de la cadera sin necesidad de cortar el hueso), el 14 de agosto de 1864 en el Hospital de San Pablo. ${ }^{12}$ El desafortunado fue un jornalero de 25 años que al estar realizando 
su trabajo recibió una contusión en la parte superior de la pierna derecha. Al momento, presentó un dolor que se fue calmando poco a poco hasta cesar y permitirle continuar con sus actividades. Al tercer mes del incidente, le surgió un tumor que fue adquiriendo un tamaño enorme y comenzó a padecer de dolor, fiebre y escalofríos a tal grado que pedía con insistencia la amputación. El doctor Hidalgo y Carpio, al examinar la pierna, resolvió, junto con los demás médicos que lo acompañaban, practicar la desarticulación coxo-femoral, cuya operación se practicó el día mencionado por la mañana. ${ }^{13} \mathrm{Al}$ término de la misma, se trasladó al sujeto a una cama del hospital para su recuperación; en los siguientes días, se notó una mejoría en el paciente. Cuatro días después de la intervención, comenzó a tener vómitos y diarreas que lo llevaron a la muerte el 18 de septiembre. Al hacerle la autopsia, se reveló que falleció a causa de una infección purulenta como accidente inmediato de la operación.

Esta cirugía era muy atrevida y muy pocos cirujanos la hacían. En América, el primero que

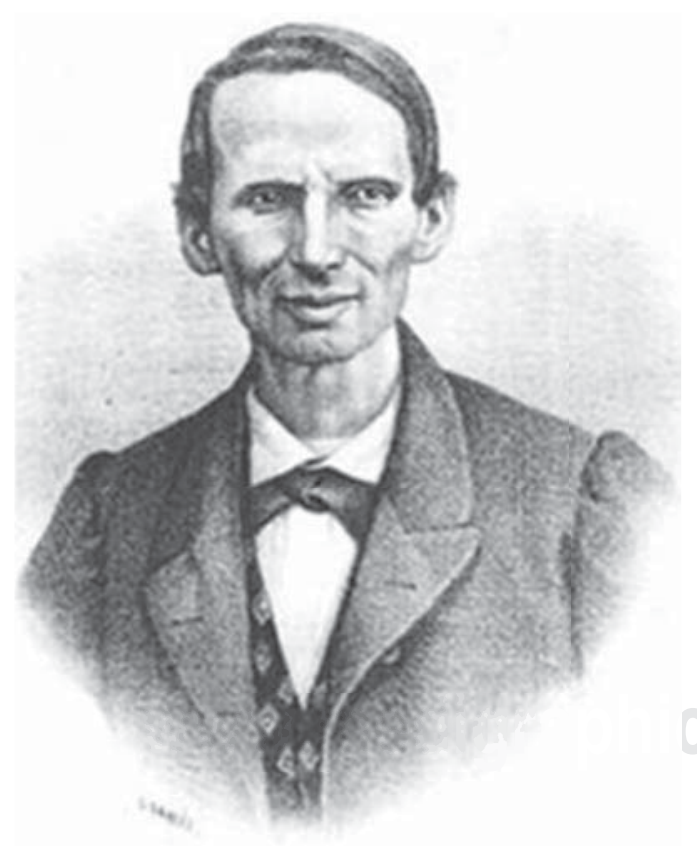

Figura 2. Luis Hidalgo y Carpio.

Fuente: Martha Eugenia Rodríguez-Pérez, en Gaceta Médica de México, Historia y Filosofía de la Medicina, Vol. 146, Núm. 2, 2009, p. 160. tuvo éxito en la desarticulación coxo-femoral fue el norteamericano Walter Brashear (17761860), quien la realizó en Bardsown, Maryland, en 1806. Su célebre compatriota, el gran cirujano Valentine Mott (1785-1865), fue el segundo que ejecutó con éxito esta operación en Nueva York en 1824. En América Latina, el primero que la llevó a cabo fue José María Barceló Villagrán el día 11 de mayo de 1864 en el Hospital de San Pablo. Para ejecutar una operación de este tipo se necesitaba un conocimiento amplio de anatomía, mucha destreza y vasta experiencia, ya que se requiere ligar arterias y cortar músculos con suma precisión. Antes de la anestesia, los médicos y cirujanos evitaban realizar este tipo de intervenciones; sólo los más diestros y experimentados se atrevían a ello. Con la llegada de la anestesia, se podían hacer grandes cirugías de este tipo, ya que al estar necrosada la pierna por arriba de la rodilla, se sugería cortar en la siguiente articulación; por ello se pensó en cortar en la articulación de la cadera o coxofemoral. El doctor Francisco Montes de Oca, que se ha mencionado con anterioridad, fue uno de los pocos cirujanos que se atrevió a llevar a cabo esta intervención. Los cirujanos franceses, estando en el sitio de Puebla, se sorprendieron por encontrar hospitales de sangre en la ciudad establecidos para atender por igual a los mexicanos y franceses con operaciones de alta cirugía hechas por Montes de Oca y el doctor Juan Navarro. ${ }^{4}$

Luis Hidalgo y Carpio murió en la Ciudad de México el 12 de mayo de 1879. El destacado cirujano vivió, como todos los demás de su profesión, una época en la que se gestaron una serie de avances tanto en el campo de la cirugía como en la medicina, donde se introdujo el concepto anatomopatológico (el cual establecía que la enfermedad se localizaba en un determinado sitio del organismo y que se descubría a través de los síntomas y los signos) y el uso de métodos diagnósticos como la percusión, la palpación y la auscultación, puestos en práctica inicialmente por el clínico Miguel Francisco Jiménez. ${ }^{11}$ No olvidemos la aparición de la asepsia y la anestesia, que vinieron a revolucionar el mundo de la cirugía, rama de la medicina que fue objeto de gran interés para Carpio, ya que su buen juicio quirúrgico lo llevó 
a realizar uno de los procedimientos quirúrgicos difíciles para la época: la desarticulación escápulo-humeral.

\section{Tobías Núñez}

Otro de los prominentes médicos mexicanos que en su larga trayectoria como médico-cirujano resolvió problemas de índole ortopédica fue el doctor Tobías Núñez (1845-1909) (Figura 3). Asignado como director del Hospital Juárez el 4 de octubre de 1886, llevó a cabo en este lugar su primera operación: luxación completa hacia adelante y hacia adentro de la extremidad superior del radio en la persona de Néstor Vargas, rebocero de 24 años de edad; después de varias maniobras para tratar esta lesión, pudo reducir la luxación con excelentes resultados. ${ }^{14}$ Su autor la consideró una operación un tanto extraña al no estar descrita por otros autores, y para estar seguro de no equivocarse, tuvo la supervisión de dos grandes médicos: Francisco Montes de Oca y Luis Muñoz, quienes aprobaron la maniobra aplicada por Tobías Núñez para reducir la luxación.

Escribió para la Gaceta Médica de México unas palabras sobre el pronóstico y tratamiento de las luxaciones que con más frecuencia se presentaban en la práctica, como las del hombro, las coxo-femorales y las de la mandíbula inferior. En cada una de estas lesiones da una explicación detallada y el tipo de curación que se debía aplicar para su mejoría. ${ }^{15}$ También escribió un artículo sobre las heridas contusas que lesionan a las articulaciones y la importancia de hacer inmediatamente un diagnóstico preciso. ${ }^{16}$ En ese artículo, Tobías Núñez menciona que las heridas de las articulaciones por machucamientos o armas de fuego fueron las lesiones con el mayor número de casos gracias a las ruedas de los coches de los tranvías o los ferrocarriles de vapor al pasar sobre los miembros de los individuos y por las revoluciones que asolaban a nuestro país, igual que las riñas callejeras entre individuos, generalmente ebrios. El doctor Domingo Orvañanos, catedrático de la Escuela Nacional de Medicina, comentaba que cada año se producían alrededor de 600 casos de atropellamiento producidos por los tranvías eléctricos, siendo las piernas y los brazos los más afectados. Ni la tuberculosis ni el tifo producían tantas lesiones. ${ }^{17}$
Pongamos como ejemplo la ocasión en que al doctor Tobías Núñez se le presentaron en el Hospital Juárez dos pacientes con heridas traumatizantes: uno por machucamiento en el codo izquierdo que afectaba la articulación, y el otro que recibió una herida por arma de fuego en la rodilla, con afectación de la articulación. En ambos casos se hizo primero una revisión de las heridas con ayuda de unas candelillas elásticas para determinar la gravedad de la lesión. De acuerdo con el autor, con ayuda de estas candelillas, se pudo llegar hasta lo profundo de la herida y reconocer el proyectil; si la herida fue por machucamiento, se exploró introduciendo el dedo, pero en ocasiones, por la estrechez de la lesión, fue necesaria la ayuda de la candelilla para reconocer hasta dónde estaba desprendida la piel, si abajo de ella había coágulos sanguíneos o si los músculos se encontraban desgarrados. Reconociendo la gravedad de las heridas y los daños producidos, se procedió a la curación, ya fuera extrayendo el proyectil para el segundo caso o aplicando la amputación para el primero. Por la gravedad

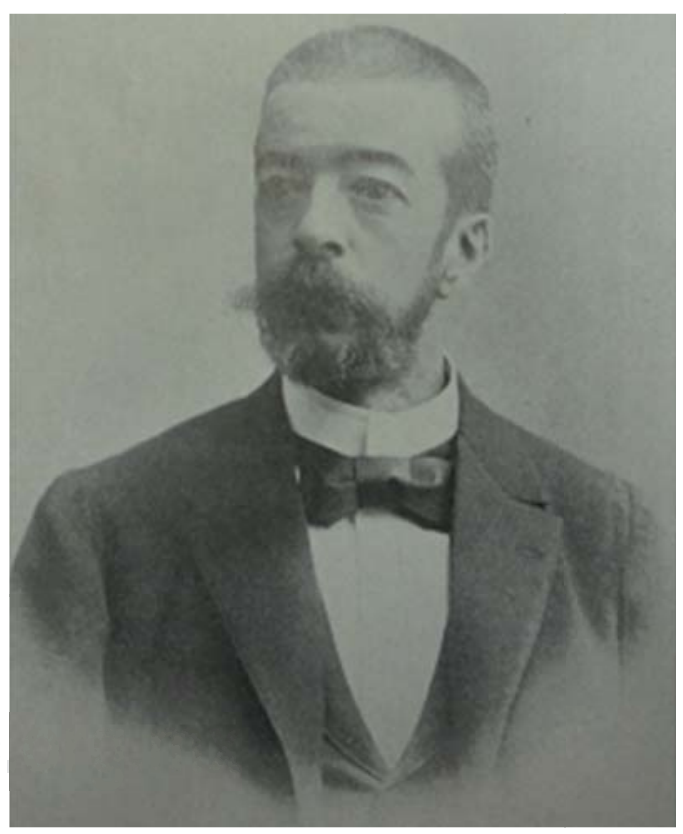

Figura 3. Tobías Núñez.

Fuente: Expediente de Médicos de la Academia Nacional de Medicina. Exp. 166-A. Biblioteca de la Academia Nacional de Medicina del Hospital Centro Médico Nacional Siglo XXI, Cd. México. 
de las heridas y por infección, a los pocos días, ambos individuos murieron.

No hay que olvidar que al doctor Tobías se le debe la primera radiografía tomada en la Ciudad de México, el 29 de octubre de 1896 en la sala 11 del Hospital Juárez. La radiografía se la tomó a una mujer que sufrió un traumatismo en el codo derecho el 11 de agosto de 1896, por lo que quedaron inhabilitados los movimientos de la articulación lesionada y el antebrazo en semiflexión. El doctor Núñez obtuvo una magnífica radiografía que demostraba una luxación del codo. ${ }^{12}$ En conclusión, después de los Estados Unidos, México fue el segundo país en el continente americano donde se usaron los rayos $\mathrm{X}$.

\section{Eduardo Liceaga Torres}

Sin embargo, estos médicos no fueron los únicos que incursionaron en operaciones de tipo ortopédico (amputaciones de extremidades, desarticulaciones de hombro y cadera, luxaciones del hombro o de la extremidad superior del radio, fracturas de la columna vertebral, resecciones óseas, extirpación de tumores óseos, tratamientos contra el mal de Pott o pie zambo, escoliosis). Otro de ellos fue Eduardo Liceaga Torres (1839-1920) (Figura 4), sobrino del ilustre médico Casimiro Liceaga, director de la Escuela Nacional de Medicina de 1902 a 1911, fundador del Hospital General de la Ciudad de México el 5 de febrero de 1905 y precursor de los estudios sobre hidrofobia al recibir de manos del propio Luis Pasteur un cerebro de conejo inoculado con el virus de la rabia con el fin de emprender las tareas necesarias para elaborar la vacuna antirrábica. ${ }^{18}$

Entre sus tantas actividades como médico, atendió un caso de mal de Pott por osteítis central de los cuerpos de las vértebras dorsales en un joven de 17 años. ${ }^{19} \mathrm{Al}$ parecer, esta es la primera noticia registrada sobre la tuberculosis de la columna vertebral (mal de Pott) en México. Existen evidencias en el Lienzo de Tlaxcala (S. XVI), donde se aprecia un personaje jorobado haciendo la defensa de un teocalli, o figuras de barro prehispánicas desenterradas que presentan deformidad dorsal, aparentemente por tuberculosis, con lo que se puede deducir que la enfermedad es más antigua en
América de lo que se cree. El primer informe completo sobre la infección tuberculosa de la columna fue hecho por el cirujano británico Percival Pott en 1779, por lo que mereció que la enfermedad llevara su nombre: mal de Pott. ${ }^{20}$ El mal de Pott, enfermedad viral que afecta las articulaciones intervertebrales, fue presentado en la Gaceta Médica de México por Eduardo Liceaga en 1878. Al estar laborando en el Hospital de San Andrés, le consultó por la mañana un joven de 17 años, de salud bastante delicada. Al revisarlo, notó un tumor que se extendía de la espina del omoplato a las últimas vértebras lumbares. ${ }^{19} \mathrm{Al}$ pedir consejo a su compañero, el doctor Rafael Lavista, cirujano del mismo hospital (quien también practicó la desarticulación de las más grandes articulaciones, como la coxofemoral), le sugirió operarlo de inmediato, lo cual realizó con éxito.

Eduardo Liceaga también trató en el año de 1880 un caso de luxación hacia arriba de la extremidad interna de la clavícula (hoy acromioclavicular), en un hombre de treinta

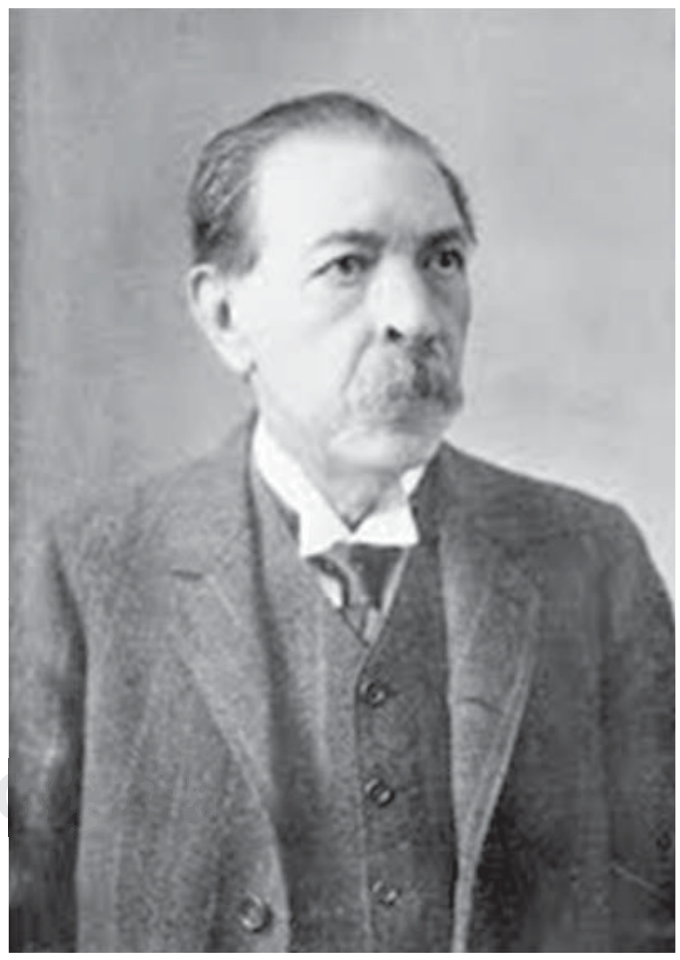

Figura 4. Eduardo Liceaga.

Fuente. http://commons.wikimedia.org/wiki/Eduardo_ Liceaga.png 
años empleado en un negocio de ropa. Al intentar cargar un bulto $y$, al mismo tiempo, atender el llamado de un compañero, el peso del bulto se le vino hacia abajo, arrastrando el brazo izquierdo hacia el piso y produciéndole un terrible dolor en la clavícula izquierda, que intentó corregir con ayuda de un vendaje. Al no disminuir los dolores, recurrió a Liceaga, que lo trató con la técnica de reducción y un vendaje que él mandó a construir. ${ }^{21}$ La lesión de la articulación acromioclavicular es una de las más frecuentes, muy común en accidentes de auto o traumas de alto impacto. No fue una operación innovadora, pero sí fue él uno de los pocos médicos mexicanos en practicarla durante esa época, ya que fue rara la ocurrencia de este tipo de luxación. Solamente se tenía el conocimiento de siete casos, tratados por el cirujano americano Frank Hastings Hamilton y los médicos franceses Alexis Boyer, JosephFrançois Malgaigne y Charles-Emmanuel Sédillot. $^{22}$ Liceaga presentó en el décimo Congreso Médico Internacional de 1890 el texto "Caso de ex-articulación del fémur hecha en cuatro tiempos diferentes y con buen éxito". ${ }^{23}$ En el año de 1894 se le presentó nuevamente un caso de mal de Pott, pero ahora en una mujer de 20 años, a quien trató nuevamente con excelentes resultados. ${ }^{24}$

Eduardo Liceaga murió a la edad de 81 años el 14 de enero de 1920, dejando un vacío en la medicina mexicana. No sólo fue un médico que contribuyó con artículos originales en las diversas revistas médicas de finales del siglo XIX, también fue un sanitarista y visionario que impulsó a la ortopedia al permitir que en el Hospital General de México se estableciera no sólo un servicio enfocado al manejo de las enfermedades de los huesos, sino también un área de ejercicios médicos y físicos (medicina de rehabilitación) donde los amputados, fracturados o aquellos con alguna enfermedad crónico-degenerativa como las artropatías tuvieran la oportunidad de recuperar y mejorar con la ayuda de ejercicios y aparatos ortopédicos (prótesis y ortesis) su capacidad funcional, física, y psíquica, para facilitar su capacidad laboral y su incorporación social; asimismo, la rehabilitación se enfocó a personas que presentaban lesiones o traumatismos severos (como esguinces, luxaciones, lumbalgias o problemas musculares) que les impedían tener una óptima calidad de vida. La rehabilitación es el complemento moderno e indispensable de la cirugía de trauma. ${ }^{25}$

\section{Luis Muñoz González}

Como ya hemos visto, el tratamiento de las heridas y fracturas del sistema musculoesquelético está profundamente ligado a la evolución de la medicina y cirugía del país, ya que hasta la mitad del siglo XX, la cirugía ortopédica y traumatología eran parte de la cirugía general, y quienes atendían este tipo de padecimientos eran los cirujanos generales.

Cuando a alguno de estos médicos se le presentaba un caso de fractura o una enfermedad osteoarticular, los recursos terapéuticos a utilizar no habían cambiado mucho, seguían siendo los mismos desde siglos anteriores. Se utilizaban tablillas delgadas, baquetas de suelas de zapatos o cartones cortados en forma de tablilla para envolver con algodón el miembro fracturado; era muy recurrente que el paciente tuviera que tolerar una mala curación por parte del cirujano.

Uno de los médicos mexicanos que representó el cambio entre los cirujanos romancistas a los titulados médicos-cirujanos de la segunda mitad del siglo XIX (de cuya mayoría fue maestro) fue el doctor Luis Muñoz (Figura 5). Él, al observar los terribles tratamientos que se aplicaban tratando de remediar una fractura, utilizó su gran ingenio, herencia de su padre José Miguel Muñoz González, para inventar una máquina para fracturas de miembro inferior; esta mantenía fija la extremidad ante casos de fracturas no expuestas, lo que permitía que el hueso soldara.

Fue un destacado médico y maestro de la Escuela de Medicina, catedrático de la materia de Patología Externa en la escuela del mismo nombre y cirujano del Hospital de San Andrés. Fue distinguido alumno de la antigua Escuela de Cirugía, y apenas se estaba recibiendo en este campo cuando, en el año de 1837, emprendió en compañía del doctor José María Vértiz un viaje a Europa para perfeccionarse en sus estudios. Ya en París, el joven cirujano, ávido de saber, empezó a seguir de cerca las lecciones de profesores eminentes de aquella 
facultad. De vuelta a su patria, desempeñó algunas cátedras, como la de Clínica Externa, que impartió de 1841 a 1843; la de Anatomía, que enseñó de 1843 a 1844; la de Operaciones, en 1849, y por fin, la de Patología Externa, su ramo predilecto. ${ }^{2}$

Entre sus numerosas aportaciones al campo ortopédico, presentó en 1875 ante la Academia de Medicina un aparato para el tratamiento de las fracturas del fémur (Figura 6). Este tipo de fracturas representó un problema de importancia sanitaria por su elevada frecuencia y la morbimortalidad y carga social que generaban. En el medio urbano comenzaron a darse casos de fractura de este tipo por las caídas de altura de edificios o por accidentes de tranvías, ferrocarriles o industriales. Si el hueso presentaba fractura expuesta, se amputaba sin remedio; para los casos de fractura no expuesta, se "jala-

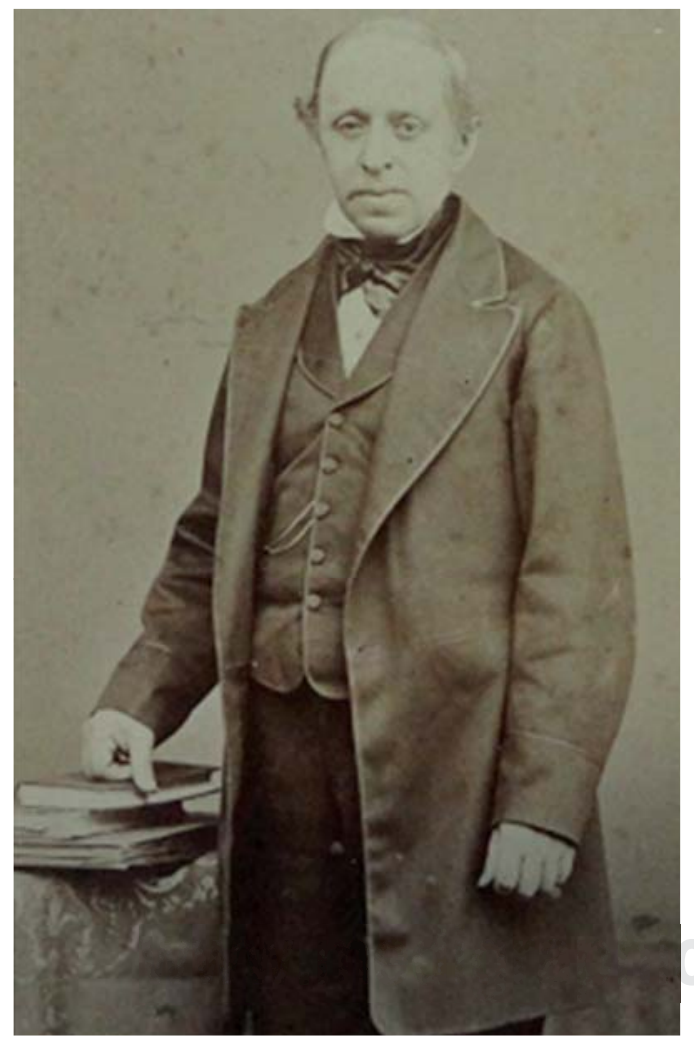

Figura 5. Luis Muñoz.

Fuente: Expediente de Médicos de la Academia Nacional de Medicina. Exp. 22. Biblioteca de la Academia Nacional de Medicina del Hospital Centro Médico Nacional Siglo XXI, Cd. México. ba", ponían a tracción. La propuesta del doctor Muñoz permitió que dicho hueso tuviera una mejoría al permitir su correcta solidificación.

Este aparato, al que Muñoz llamó "contentivo", se colocaba sobre todo de "sustentación", que en forma de pilar podía subir o descender la pierna a voluntad. Luis Muñoz hizo la presentación de su invento, comentó simultáneamente las ventajas e inconvenientes de otros similares que los médicos de la época usaban para las fracturas del cuerpo del fémur, y tras las pruebas pertinentes, el invento fue aprobado. Con esta contribución, Muñoz reforzó los conocimientos y primeros ensayos de la cirugía moderna mexicana. ${ }^{26} \mathrm{El}$ mismo Muñoz confirmó el éxito de su aparato: "He aplicado mi aparato en enfermos en quienes podían temerse accidentes inflamatorios graves por haber sido ocasionada en ellos la fractura por causa directa que obró con mucha energía. En uno de estos casos, la rueda grande de un coche había pasado a través del muslo izquierdo del enfermo, produciendo una fractura conminutiva; en otro paciente, que ha estado recientemente en el número 7 de la sala de cirugía del Hospital de San Andrés, la fractura fue ocasionada por una caída de un lugar muy elevado, sobre el muslo izquierdo: en ambos casos había gran derrame y tumefacción acompañados de dolores muy agudos. Aplicado inmediatamente el aparato, comenzaron luego a moderarse los dolores y continuaron decreciendo rápidamente; la tu-

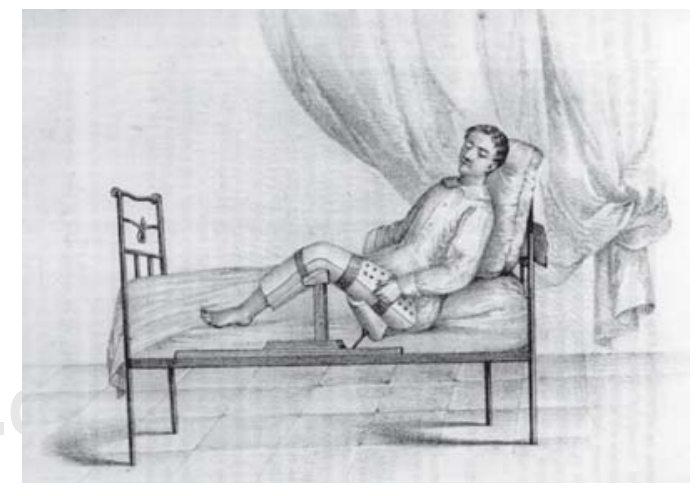

Figura 6. Aparato para fracturas.

Fuente: Luis Muñoz, "Nuevo aparato para el tratamiento de las fracturas del cuerpo del fémur", en Gaceta Médica de México, Cirugía, Tomo. X, Núm. 23, 1. ${ }^{\circ}$ de diciembre de 1875. pp. 447. 
mefacción se disipó pronto y la consolidación marchó con regularidad; ningún accidente sobrevino. Con este aparato, se puede obtener el restablecimiento de las funciones del miembro sin que quede deformidad aparente ni claudicación, con tanta seguridad como la que se prometen los que emplean la extensión continua y con la grandísima ventaja de evitar a los enfermos lo penoso de aquella posición y de los medios que la mantienen". ${ }^{26}$

Murió este distinguido cirujano el 19 de septiembre de 1873. El tratamiento del tifo fue el culpable de esta adversidad, cuya cura buscaba este médico con insistencia. Desconozco por el momento si el aparato de Muñoz fue utilizado en otros casos o si fue adoptado por algún hospital. En el Hospital de San Pedro, en la ciudad de Puebla de los Ángeles, se tiene registrado el uso de un aparato para aliviar fracturas de miembro inferior. Debemos agradecer a los médicos y cirujanos de este hospital el haber llevado un registro a detalle de las enfermedades y lesiones que se les presentaban; gracias a esta actividad, se puede leer entre numerosas observaciones cómo se trataba a los fracturados.

No tengo información que me permita confirmar si el aparato que se utilizó en el Hospital de San Pedro fue el de Muñoz o quizás algún otro. Muñoz no fue el único en inventar aparatos para fracturas; el médico parisino y jefe de sanidad del ejército francés Carlos Ehrmann presentó en la Gaceta Médica de México de 1866 un aparato para la fractura del fémur con muy buenos resultados. El médico aseguraba que su instrumento era recomendable en este tipo de fracturas, ya que inmovilizaba por completo el miembro fracturado por medio de ataderas que se colocaban entre el miembro fracturado y cintura del sujeto. ${ }^{27}$

\section{CONCLUSIÓN}

Durante el siglo XIX no existieron cirujanos que se dedicaran exclusivamente al tratamiento de las entidades óseas y articulares; tampoco hubo servicios exclusivos de dicha disciplina; el único indicio lo idearon los eventos nacionales e internacionales donde se exponían aquellas enfermedades denominadas "ortopédicas". En los años que siguieron a 1880, una nueva gene- ración de cirujanos con mejores conocimientos clínicos y anatómicos, así como los adelantos de la anestesia y el perfeccionamiento de la asepsia, hicieron que se pudieran manejar casos antes intratables, limitando el manejo de la amputación a casos de severa hemorragia de miembro o sutura de las heridas y estabilización de las fracturas. El último tercio del siglo XIX se caracterizó por la intrepidez del manejo del traumatismo de abdomen y cabeza, así como el intento de salvar las extremidades. Las fracturas o lesiones de los miembros fueron manejadas con ferulizaciones.

\section{REFERENCIAS}

1. Martínez-Cortés F. La medicina científica en México y el siglo XIX mexicano. México: SEP/Fondo de Cultura Económica; 2003.

2. Flores y Troncoso FA. Historia de la medicina en México desde los indios hasta la presente. Tomo III. México: Instituto Mexicano del Seguro Social; 1992.

3. La Escuela de Medicina. Periódico dedicado a las Ciencias Médicas. Tomo V. 1883-1884; (3): 44.

4. Heliodoro-Valle R. La cirugía mexicana del siglo XIX. México: Tipográfica Lag; 1942.

5. Montes de Oca F. Amputación de la mano, modificación en la desarticulación del hombro, operación de la fimosis y extirpación del testículo [Tesis]. México: UNAM; 1874.

6. Rodríguez de Romo AC, Castañeda-López G, RoblesValencia R. Protagonistas de la medicina científica mexicana 1800-2006. México: UNAM; 2008.

7. Arechiga $\mathrm{H}$, Somolinos J. (Comp.) Contribuciones mexicanas al conocimiento médico. México: Fondo de Cultura Económica; 1993.

8. Antología de escritos histórico-médicos del Dr. Francisco Fernández del Castillo. Tomo I. México: Facultad de Medicina UNAM; 1982.

9. De la Garza-Villaseñor L. Dominique Jean Larrey. La cirugía militar de la Francia revolucionaria y el Primer Imperio. Cir Gen. 2004; 26: 59-66.

10. Hidalgo-Carpio L. ¿Cuál es, en los hospitales de México, la gravedad de la desarticulación escápulohumeral? Gac Méd Méx. 1865; (10): 161.

11. Rodríguez-Pérez ME. Luis Hidalgo y Carpio, editor de Gaceta Médica México (1818-1879). Gac Méd Méx. 2009; 146: 159-166.

12. Velasco-Ceballos R. El Hospital Juárez, antes hospital Municipal de San Pablo. México: Archivo Histórico de la Secretaría de Salubridad y Asistencia; 1947.

13. Hidalgo-Carpio L. Una observación de desarticulación coxo-femoral. Gac Méd Méx. 1865; 21: 346-348.

14. Núñez T. Luxación completa hacia adelante y hacia adentro de la extremidad superior del radio. Gac Méd Méx. 1876; 18: 352-356.

15. Núñez T. Unas cuantas palabras sobre el pronóstico y tratamiento de las luxaciones que con más frecuencia se presentan en la práctica. Gac Méd Méx. 1893; 10: 329-338. 
16. Núñez T. Heridas contusas que interesan las articulaciones. Gac Méd Méx. 1890; 23: 461-474.

17. Orvañanos D. De algunos accidentes causados por los tranvías eléctricos. Gac Méd Méx. 1905; (1): 12-14.

18. Rodríguez ME. La Escuela Nacional de Medicina. 1833-1910. México: UNAM; 2008.

19. Liceaga E. Mal vertebral de Pott por osteítis central de los cuerpos de las vértebras dorsales. Gac Méd Méx. 1878; 18: 351-357.

20. Gutiérrez-Báez VR. Tuberculosis de la columna vertebral (mal de Pott) evolución postquirúrgica en el H.T.O.P. [Tesis]. Puebla: UNAM; 1991.

21. Liceaga E. Luxación hacia arriba de la extremidad interna de la clavícula. Gac Méd Méx. 1881; 17: 291-298.

22. Malgaigne JF. Traité des fractures et des luxations. Tomo II. París: Chez J-B. Bailliere; 1855.

23. Liceaga E. Caso de ex articulación del fémur, hecha en 4 tiempos diferentes y con buen éxito. Gac Méd Méx. 1890; 18: 374.
24. Liceaga E. Mal de Pott. Tratamiento por la inmovilidad en el canal de Bonnet. Gac Méd Méx. 1896; (1): 601604.

25. Díaz de Kuri M, Viesca-Treviño C. Historia del Hospital General de México. México: Gráfica Creativa y Diseño; 1991.

26. Muñoz L. Nuevo aparato para el tratamiento de las fracturas del cuerpo del fémur. Gac Méd Méx. 1875; 23: 447-455.

27. Ehrmann. Aparato para la fractura del cuello del fémur. Gac Méd Méx. 1866; (1): 12-16.

Correspondencia:

José Luis Gómez De Lara

Centro de Estudios Históricos.

Colegio de Michoacán, AC.

Martínez de Navarrete Núm. 505,

Las Fuentes, 59699, Zamora, Mich.

Teléfono: 2221209321

E-mail: amoyot|@hotmail.com 